\title{
Research on Mechanical properties of the composites polymer fiber reinforced: A Case Study
}

\author{
Yanjie Zhou, ${ }^{1, a}$, Min Wen ${ }^{2, a}$ \\ ${ }^{1}$ College of Mathematical and Computer Science Jiangxi Science \& Technology Normal University \\ Nanchang, China 330031 \\ ${ }^{1}$ Department of Civil and Architectural Engineering Nanchang Institute of Technology \\ Nanchang, China 330099 \\ a zhouyanjie1111@126.com
}

Key words: Fiber reinforced; Composites; Case Study; Mechanical Properties

\begin{abstract}
Fiber reinforced polymer Resin matrix composites have the good performance, and it is widely used in various fields to release the impact load. Over the past era of time, natural fibers have gained bursting attention than ever before from all the other research areas around the world. These natural fibers provide a plenty of advantages and strengthen than the other fibers. In this paper, we conduct a case study of the synthesis and mechanical properties of novel series of green composites including Hibiscus sabdariffa fiber as a reinforcing material in urea-formaldehyde (UF) resin based polymer matrix has been reported. Static mechanical properties of the previous randomly oriented intimately mixed Hibiscus sabdariffa fiber reinforced polymer composites such as tensile, compressive and wear properties are investigated as well. Initially urea-formaldehyde resin prepared is subjected to evaluation of its optimum mechanical properties. Then reinforcing of the resin with Hibiscus sabdariffa fiber is accomplished in three different forms: particle size, short fiber and long fiber by employing optimized resin. Proposed research reveals that mechanical properties such as tensile strength, compressive strength and wear resistance of the urea-formaldehyde resin increases to considerable extent when reinforced with the fiber. Thermal and morphological studies of the resin and bio-composites have also been conducted.
\end{abstract}

\section{Introduction}

The advantages of natural fibers over traditional reinforcing materials such as glass fiber, carbon fiber etc are their specific strength properties, easy availability, light weight, ease of separation, enhanced energy recovery, high toughness, non-corrosive nature, low density, low cost, good thermal properties, reduced tool wear, reduced dermal and respiratory irritation, less abrasion to processing equipment, renewability and biodegradability (Lawton and Fanta 1994; Simon et al 1998; Chauhan et al 1999, 2001; Joshi et al 2004; Singha et al 2004)[1-5]. It has been observed that natural fiber reinforced composites have properties similar to traditional synthetic fiber reinforced composites. Natural fiber composites have been studied and reviewed by a number of researchers (Dufresne 1997; Dufresne and Vignon 1998; Mao et al 2000; Kaith et al 2003; Nakagaito et al 2004, 2005; Bhatnagar and Sain 2005)[6-9]. During the past decade, a number of significant industries such as the automotive, construction or packaging industries have shown massive interest in the progress of new bio-composites materials. One of the most appropriate examples of this is the substitution of inorganic fibres such as glass or aramid fibers by natural fibers (Bledzki and Gassan 1999; Chauhan et al 1999; Chakraborty et al 2006)[10-12]. All these properties have made natural fibers very attractive for various industries currently engaged in searching for new and alternate products to synthetic fiber reinforced composites.

The properties of natural fibers can vary depending on the source, age and separating techniques of the fibers. Hibiscus sabdariffa, an annual fiber plant, has been found to be an important source of 
fibers for a number of applications since good old days. The bast fiber has high potential as a reinforcing fiber in polymer composites. Hibiscus sabdariffa plant fiber is abundantly found in the Himalayan region, especially in Himachal Pradesh. Traditionally, this fibrous material belonging to Himalayan region is being used by the local people for making low cost articles like socks, boots, mats, ropes, bags etc. The literature review has shown scanty information on the application of this fiber as reinforcing material in the polymer composites. Our research group has successfully improved the properties of a number of fibres such as flax, Saccharum cilliare, Hibiscus sabdariffa, rayon and Cannabis indica by various techniques such as graft-copolymerization etc (Chauhan et al 1999, 2000a, b, 2001; Singha et al 2002, 2004, 2006; Kaith et al 2003, 2007a; Kaith and Kalia Susheel 2007)[13-14]. Keeping in view the easy availability of this new fiber a comprehensive research work has been initiated in our laboratory on synthesis and study of properties of Hibiscus sabdariffa fiber reinforced urea- formaldehyde (U-F) resin matrix based bio-composites.

\section{Concepts and Experiment of Our Approach}

Mechanism of synthesis of urea-formaldehyde resin Mechanism of polymerization reaction follows two steps. First step is the formation of methylol urea from the reaction between urea and formaldehyde. Since urea is tetra functional so initial reaction due to presence of sufficient ratio of formaldehyde to urea may lead to the formation of tetra methylol derivative of urea (as shown in figure.1). The rate at which methylol urea (I) and (II) formation takes place depends upon temperature, $\mathrm{pH}$ and the ratio of formaldehyde to urea $(\mathrm{F} / \mathrm{U})$. To control the reaction and to favor the formation of dimethylol urea, the reaction condition must be slightly alkaline and a $\mathrm{pH}$ of 7-8 is employed (Singha and Thakur 2007). Since methylol ureas are not adhesives, condensation does not take place. So next step is the condensation of monomeric methylol urea to form polymer molecules. The reaction is carried. out at $80-90^{\circ} \mathrm{C}$ in an acidic medium ( $\mathrm{pH}$ 5.5-6). As the reaction proceeds larger molecules with cross linked structures are formed. After the completion of the reaction, neutralization $(\mathrm{pH} \mathrm{7.5-8)}$ is carried out. The condensation must be closely watched and controlled at the stages of production because if the reaction is allowed to continue cross linking will lead to the gelatization of the resin. Under acidic conditions methylol urea condense by elimination of water between either of four steps (as shown in figure.1).

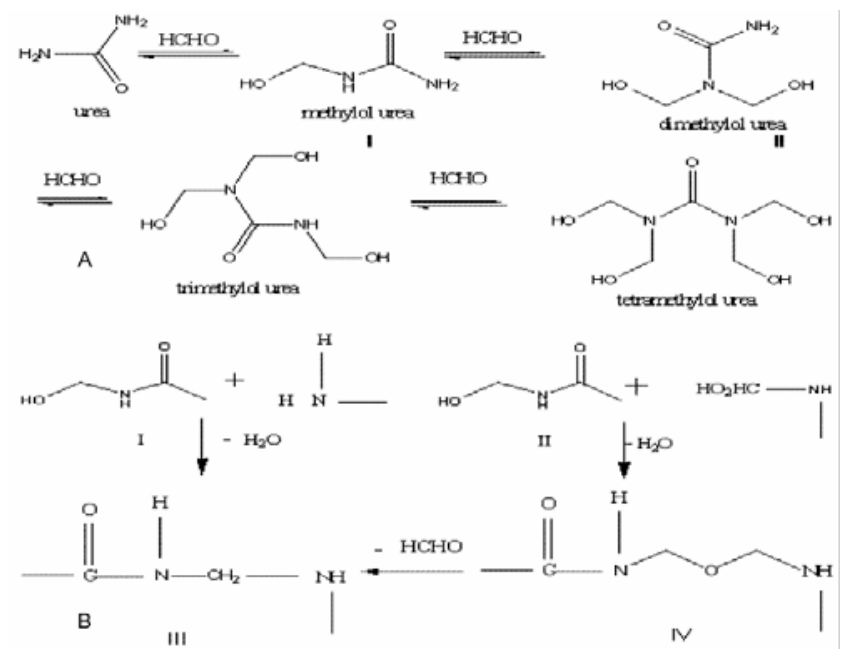

Fig. 1 Explanation of the Structure

Optimization of urea-formaldehyde resin. Tensile strength: It has been observed that U-F samples of ratio $1: 2.5$ bear maximum load at a particular applied load as compared to samples of other ratios. This ratio $(1: 2.5)$ could bear a load of $128.125 \mathrm{NF}$ with an extension of $1.84 \mathrm{~mm}$ (figure.2). On the other hand, samples of other ratios bear low loads. Compressive strength: It is evident from figure. 2 that the samples of ratio $1: 2.5$ could bear a load of $991 \mathrm{~N}$ at a compression of $3.51 \mathrm{~mm}$. Wear resistance: It has been observed that wear rate of samples of ratio $1: 2.5$ was less as 
compared to any other samples. Loss of material was due to abrasion and friction of samples with disc (figure.2). As evident from figures.2 samples of ratio $1: 2.5$ show maximum tensile and compressive strengths. Moreover, at this ratio wear rate was also very less. Therefore, this ratio was taken for further preparation of urea-formaldehyde resin and respective bio-composites.
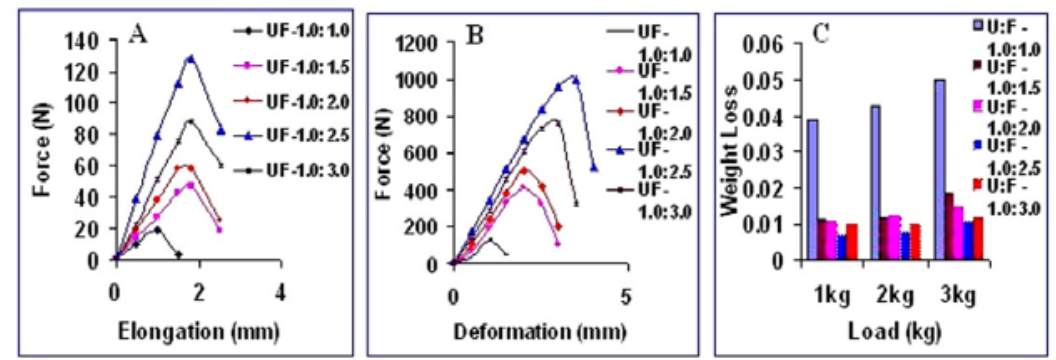

Fig. 2 Tensile Strength and Wear Resistance Curve of UF Resin

Effect of reinforcement on mechanical properties of $\mathbf{U}-\mathbf{F}$ based bio-composites: Tensile strength: It has been observed that composites with particle reinforcement showed more tensile strength which was followed by short fiber and long fiber reinforced composites (figures.3). It is clear from figures. 3 that the samples of (i) particle reinforced composite could bear a load of $332.8 \mathrm{~N}$ at an extension of $2.2 \mathrm{~mm}$, (ii) short fiber reinforced composite could bear a load of $307.6 \mathrm{~N}$ at an extension of $2.23 \mathrm{~mm}$ and (iii) long fiber reinforced composite could bear a load of $286.1 \mathrm{~N}$ at an extension of $2.28 \mathrm{~mm}$. Compressive strength: Compressive strength of UF resin matrix has been found to increase when reinforced with fiber. It has been found that with particle reinforcement, compressive strength increases to a much more extent than short and long fiber reinforcement (figures.4). It is clear that the samples of (i) particle reinforced composite could bear a load of $2586.5 \mathrm{~N}$ with a compression of 3.51 $\mathrm{mm}$, (ii) short fiber reinforced composite could bear a load of $2466.5 \mathrm{~N}$ with a compression of 3.55 $\mathrm{mm}$ and (iii) long fiber reinforced composite could bear a load of $2376.5 \mathrm{~N}$ with a compression of $3.58 \mathrm{~mm}$. Wear test: As evident from (figures.5) wear rate of UF matrix decreases appreciably when it is reinforced with Hibiscus sabdariffa fiber. It was observed that particle reinforcement decreases the wear rate to a much more extent than short and long fiber reinforcements. From these results it is clear that particle reinforcement is more effective than short and long fiber reinforcements. This may be due to larger surface area and more fiber/matrix interaction in case of particle reinforced composites Morphological study of biocomposites: Morphological results (figures.6) clearly show that there is proper intimate mixing of Hibiscus sabdariffa fibre with the synthesized resin in the biocomposites. It is clear from the micrographs that there is uniform mixing with particle reinforcement as compared to short and long fibre reinforcements.
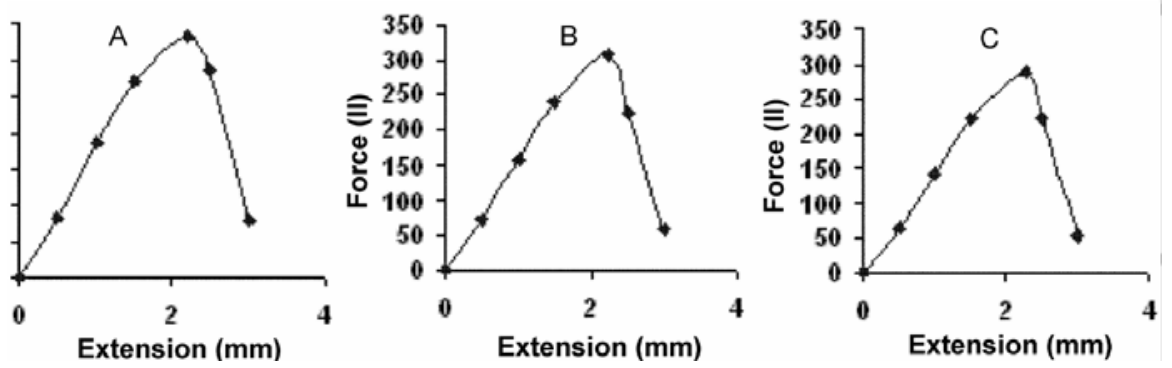

Fig. 3 Tensile Strength Curves of P-Rnf/SF-Rnf and LF-Rnf Composites 

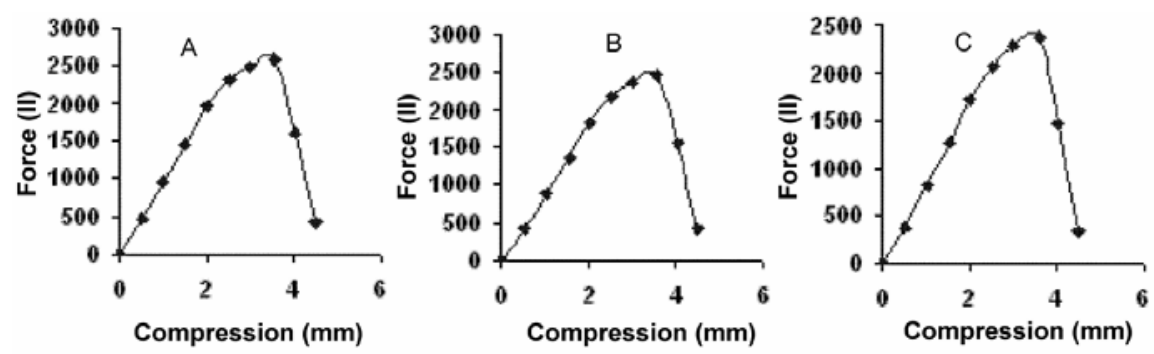

Fig. 4 Compressive Strength Curves of P-Rnf/SF-Rnf and LF-Rnf Composites
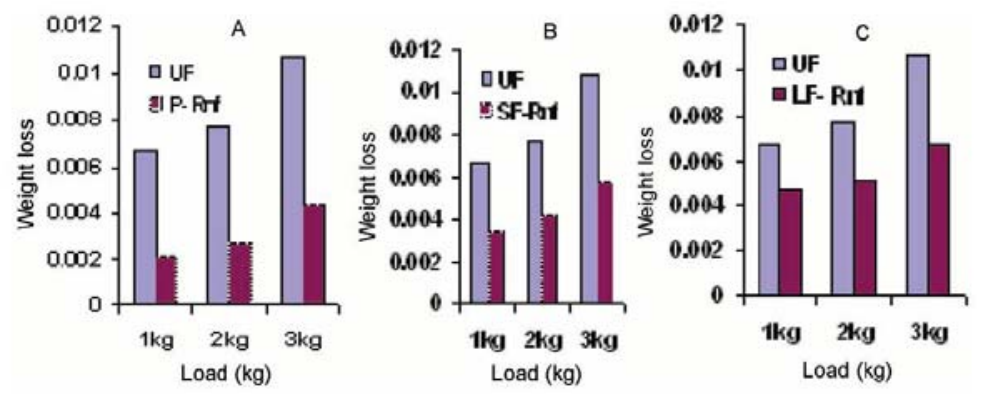

Fig. 5 Wear Resistance Curves of P-Rnf/SF-Rnf and LF-Rnf Composites

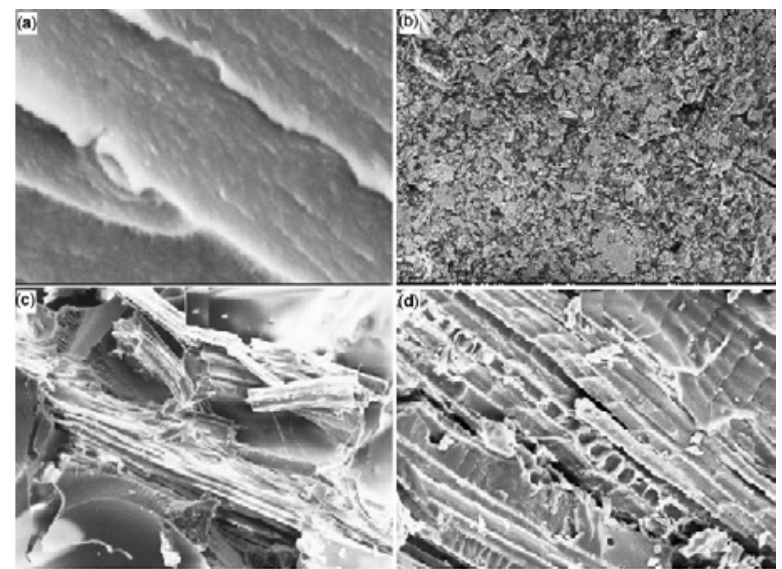

Fig. 6 SEM Images of UF Resin, P-Rnf, SF-Rnf and LF-Rnf Composites

\section{Conclusion and Final Result}

Various test methods were adapted for mechanical characterization of natural fiber reinforced polymer composites. In case of mechanical behavior particle reinforcement of the UF resin has been found to be more effective as compared to short fiber reinforcement. These results suggest that Hibiscus sabdariffa fiber has immense scope in the fabrication of natural fiber reinforced polymer composites having vast number of industrial applications.

\section{Acknowledgements}

Part of this work is supported by the youth Science Foundation Project in Nanchang Institute of Technology (2010KJ022).

\section{References}

[1] Mohd Azlan Mohd Azuan, Abdul Latif Muhamad Ridzuan, Abdullah Mohamad Zaki, Zainal Abidin Kamal Arif, Abdul Wahab Azmi. Flow behavior in the resin infusion of glass fiber reinforced polymer wind turbine blade. Advanced Materials Research, 686 (2013): 118-124. 
[2] Lu Yuan, Mei Shuang, Pi Pi-Hui, Han Tailiang, Cheng Jiang, Wen Xiu-Fang, Cai Zhi-Qi, Qian Yu. One-dimensional heat transfer study of a fiber-reinforced wind epoxy composite system in vacuum assisted resin transfer molding process. Polymer Composites, 35(6) (2014): 1031-1037.

[3] Pitarresi Giuseppe, Alessi Sabina, Tumino Davide, Nowicki Andrzej, Spadaro Giuseppe. Interlaminar fracture toughness behavior of electron-beam cured carbon-fiber reinforced epoxy-resin composites. Polymer Composites, 35(8) (2014): 1529-1542.

[4] Hu Honglin, Hao Lifeng, Wang Rongguo, Liu Wenbo, Yang Fan, Jiao Weicheng, Xu Zhonghai. Tensile properties of epoxy with microcapsules and imidazoline derivatives curing agent and interlaminar self-healing properties of carbon fiber reinforced epoxy composites. Polymers and Polymer Composites, 22(3) (2014): 293-298.

[5] Cadek, M., et al. "Morphological and mechanical properties of carbon-nanotube-reinforced semicrystalline and amorphous polymer composites." Applied Physics Letters 81.27 (2002): 5123-5125.

[6] Subagia I.D.G.Ary, Jiang Zhe, Tijing Leonard D., Kim Yonjig, Kim Cheol Sang, Lim Jae Kyoo, Lim Jae Kyoo. Hybrid multi-scale basalt fiber-epoxy composite laminate reinforced with Electrospun polyurethane nanofibers containing carbon nanotubes. Fibers and Polymers, 15(6) (2014): 1295-1302.

[7] Xu Yanhua, Yuan Xinlin, Wang Ni, Liu Zhaolin. Comparison of bending properties Co-woven-knitted and Multi-layered biaxial Weft-knitted fabric reinforced composites. Fibers and Polymers, 15(6) (2014): 1288-1294.

[8] Zhang Wei, Kanakubo Toshiyuki. Local bond stress-slip relationship between carbon fiber-reinforced polymer plates and concrete under fatigue loading. ACI Structural Journal, 111(4) (2014): 955-965.

[9] Gojny, Florian H., et al. "Influence of different carbon nanotubes on the mechanical properties of epoxy matrix composites-a comparative study." Composites Science and Technology 65.15 (2005): 2300-2313.

[10] Hafizah N.A.K., Bhutta M.A.R., Jamaludin M.Y., Warid M.H., Ismail M., Rahman M.S., Yunus I., Azman M. Kenaf fiber reinforced polymer composites for strengthening RC beams. Journal of Advanced Concrete Technology, 12(6) (2014): 167-177.

[11] Liang Meng, Wu Zhi-Min, Ueda Tamon, Zheng Jian-Jun, Akogbe Romuald. Experiment and modeling on axial behavior of carbon fiber reinforced polymer confined concrete cylinders with different sizes. Journal of Reinforced Plastics and Composites, 31(6) (2012): 389-403.

[12] Czigany, T. "Special manufacturing and characteristics of basalt fiber reinforced hybrid polypropylene composites: mechanical properties and acoustic emission study." Composites Science and Technology 66.16 (2006): 3210-3220.

[13] Zhang Rui, He Lingfeng, Li Changrong. The stress intensity factor of opening mode determined by digital image correlation. Applied Mechanics and Materials, 83(2011): 54-59.

[14] Lozano, K., J. Bonilla - Rios, and E. V. Barrera. "A study on nanofiber - reinforced thermoplastic composites (II): Investigation of the mixing rheology and conduction properties." Journal of Applied Polymer Science 80.8 (2001): 1162-1172. 